\title{
Discrete and condensed clusters-A link between molecular and solid state chemistry
}

\author{
Arndt Simon \\ Max-Plack-Institut für Festkörperforschung \\ Heisenbergstr.1, 70569 Stuttgart, Germany
}

\begin{abstract}
Metal clusters are of great interest both in molecular and solid state chemistry. They provide a smooth transition from discrete molecular species to structures with extended metal-metal bonding as illustrated with the chemistry of metal-rich compounds of the early transition metals, lanthanides, alkali and alkaline earth metals.
\end{abstract}

The structures of metals can be viewed as condensates of octahedra which are regular for fcc metals and more or less distorted for other close-packed and, in particular, bcc metals. Fragments of these frameworks of metal atom octahedra are found in a vast number of structures owned by metal-rich compounds, which are built from discrete or condensed octahedral clusters in oligomeric units, infinite single or multiple chains, layers and threedimensional networks. These octahedra are empty with a sufficiently large number of electrons available for strong metal-metal bonding. However, they are filled by interstitial atoms and thus stabilized in case of pronounced electron deficiency.

The concept of cluster condensation has provided a valuable ordering scheme for the structural chemistry of metal-rich compounds, covering such different compound classes as halides, oxided, chalcogenides of $d$ transition elements, halides of the rare earth metals, subnitrides of alkaline earth and suboxides of alkali metals. Moreover, the concept has served as a tool to enter new chemistry in the field of reduced oxoniobates and oxomolybdates as well as ternary (carbide-, hydride-) halides of the rare earth metals. Figure 1 gives a summary of some structures found in the solid state.

Instead of presenting a review on the topic "Discrete and Condensed Metal Clusters" which has to be brief and very fragmentary, repeating what has already been written, it might be more valuable to draw attention to some papers by the author covering the topic in a general $(1,2)$ way, and more specifically $(3-6)$. 

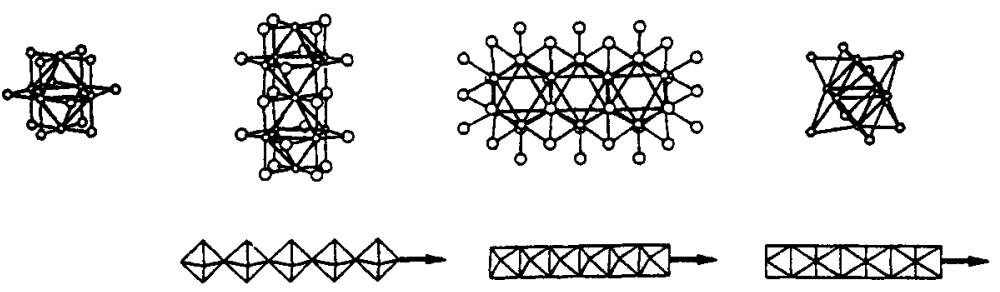

1-D
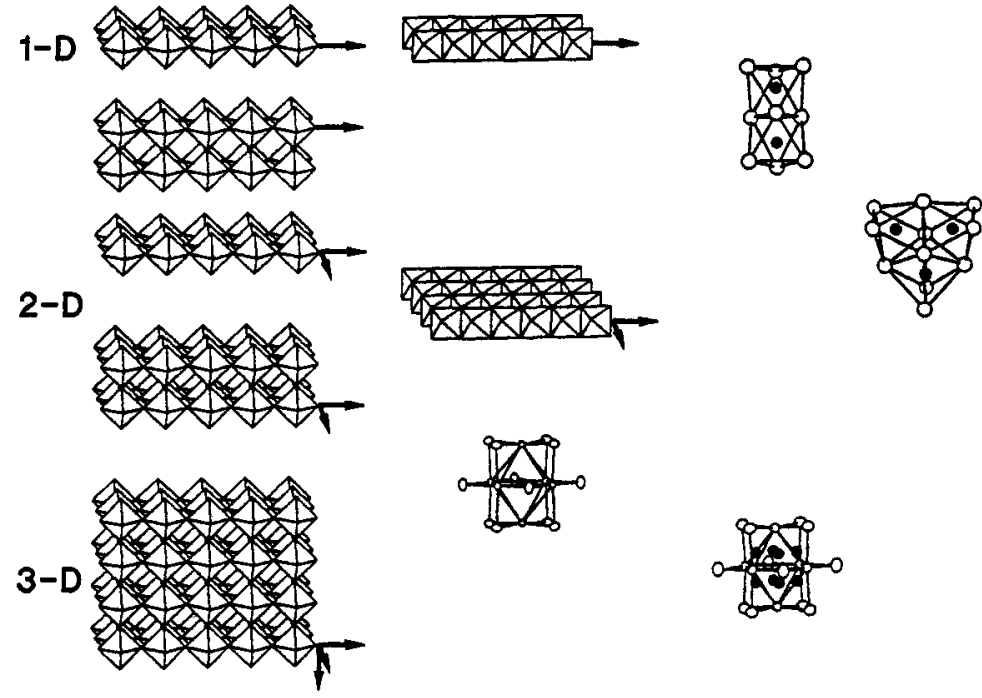

Figure $1 \quad \mathrm{Nb}_{6} \mathrm{Cl}_{12}, \mathrm{Nb}_{11} \mathrm{O}_{20}, \mathrm{Mo}_{14} \mathrm{O}_{34}, \mathrm{Nb}_{6} \mathrm{I}_{8}, \mathrm{Rb}_{9} \mathrm{O}_{2}, \mathrm{Cs}_{11} \mathrm{O}_{3}, \mathrm{Th}_{6} \mathrm{Br}_{12} \mathrm{H}_{7}, \mathrm{Th}_{6} \mathrm{Br}_{12} \mathrm{Fe}$ clusters, respectively, and condensation of such cluster types into chains, layers and frameworks with reduced compounds of $\mathrm{Nb}, \mathrm{Mo}$, rare earth metals and $\mathrm{Ba}$.

\section{References}

1. A. Simon "Clusters of Valence Electron Poor Metals - Structure, Bonding, and Properties" Angew. Chem. Int.Ed. Engl. 27, 159-183 (1988)

2. A. Simon "Discrete and Condensed Transition Metal Clusters in Solids" Clusters and Colloids - From Theory to Applications, G. Schmid ed. VCH Weinheim, New York, Basel, Cambridge, Tokyo, pp. 371-458 (1994)

3. A. Simon "Condensed Metal Clusters" Angew. Chem. Int. Ed. Engl. 20, 1-22 (1981)

4. J. Köhler, G. Svensson, A. Simon "Oxoniobates Containing Metal Clusters" Angew. Chem. Int. Ed. Engl. 31, 1437-1456 (1992)

5. A. Simon, Hj. Mattausch, G. J. Miller, W. Bauhofer, R. K. Kremer "Metal-rich Halides" Handbook on the Physics and Chemistry of Rare Earths, K. A. Gschneidner, L. Eyring eds., North Holland, Amsterdam, London, New York, Tokyo, pp. 191-285 (1991)

6. A. Simon "Structure and Bonding in Alkali Metal Suboxides" Structure and Bonding 36, 81-127 (1979) 